\title{
Detailed Seafloor Habitat Mapping to Enhance Marine-Resource Management
}

Pictures of the seafloor capture important information about the sediments, exposed geologic features, submerged aquatic vegetation, and animals found in a given habitat. With the emergence of marine protected areas (MPAs) as a favored tactic for preserving coral reef resources, knowledge of essential habitat components is paramount to designing effective management strategies. Surprisingly, detailed information on seafloor habitat components is not available in many areas that are being considered for MPA designation or that are already designated as MPAs. A task of the U.S. Geological Survey Coral Reef Ecosystem STudies (USGS CREST) project is addressing this issue.

\section{ATRIS Technology}

To expedite the documenting of seafloor habitat components, the USGS Coastal and Marine Geology Program developed the Along-Track Reef-Imaging System (ATRIS). Designed to rapidly acquire geo-located, high-resolution digital images, ATRIS can be deployed in either "shallow" or "deep" configurations from boats at least 25 feet in length (fig. 1). Shallow ATRIS has a camera and depth sounder mounted to the bottom of an adjustable pole with a GPS antenna affixed on top. It is suitable for imaging in water depths ranging from 2 to 6 meters $(\mathrm{m})$, has a maximum survey speed of 1 meter per second $(\mathrm{m} / \mathrm{s})$, and can acquire up to 20 digital images per second. Deep ATRIS has a camera and depth sounder mounted on a towed vehicle that can operate down to $27 \mathrm{~m}$. It has a maximum survey speed of $3 \mathrm{~m} / \mathrm{s}$ and can acquire up to 8 digital images per second. The same camera and acquisition software are used for both configurations. Images are displayed in real-time and are simultaneously saved on two hard drives.

ATRIS is usually operated $2 \mathrm{~m}$ above the seafloor, yielding images that cover
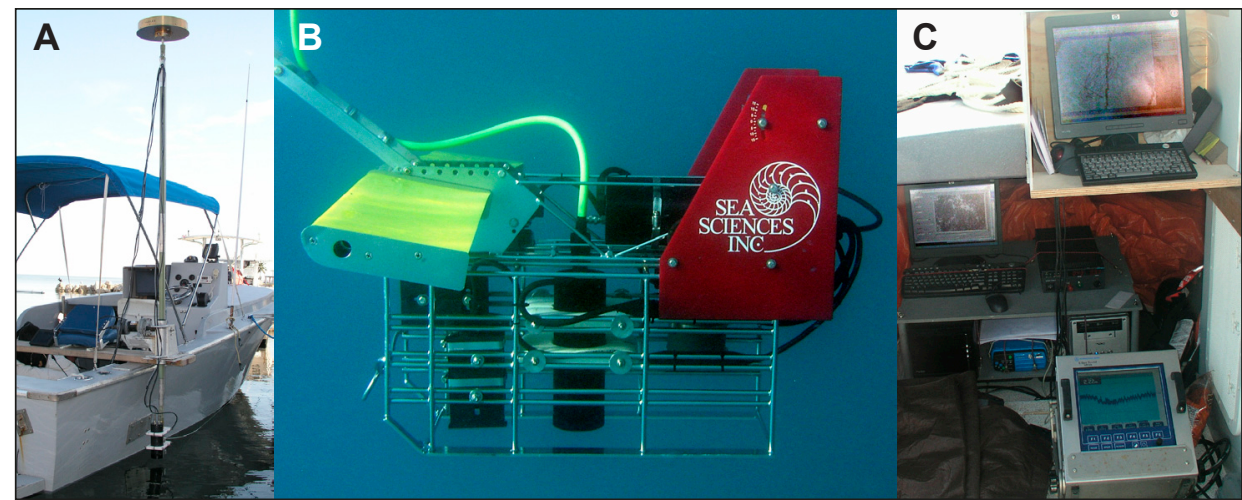

Figure 1. (A) Shallow ATRIS with camera and depth sounder mounted on the bottom of an adjustable pole with GPS antenna on the top. (B) Deep ATRIS with camera, depth sounder, compass, and roll-pitch-heave sensors mounted on a towed vehicle. A GPS antenna is mounted on the boat. (C) ATRIS control center, which includes an Ashtech GPS receiver, the image acquisition computer, the navigation computer, a KVH digital compass, and a Marimatech sounder. Photo credits: David G. Zawada, USGS.

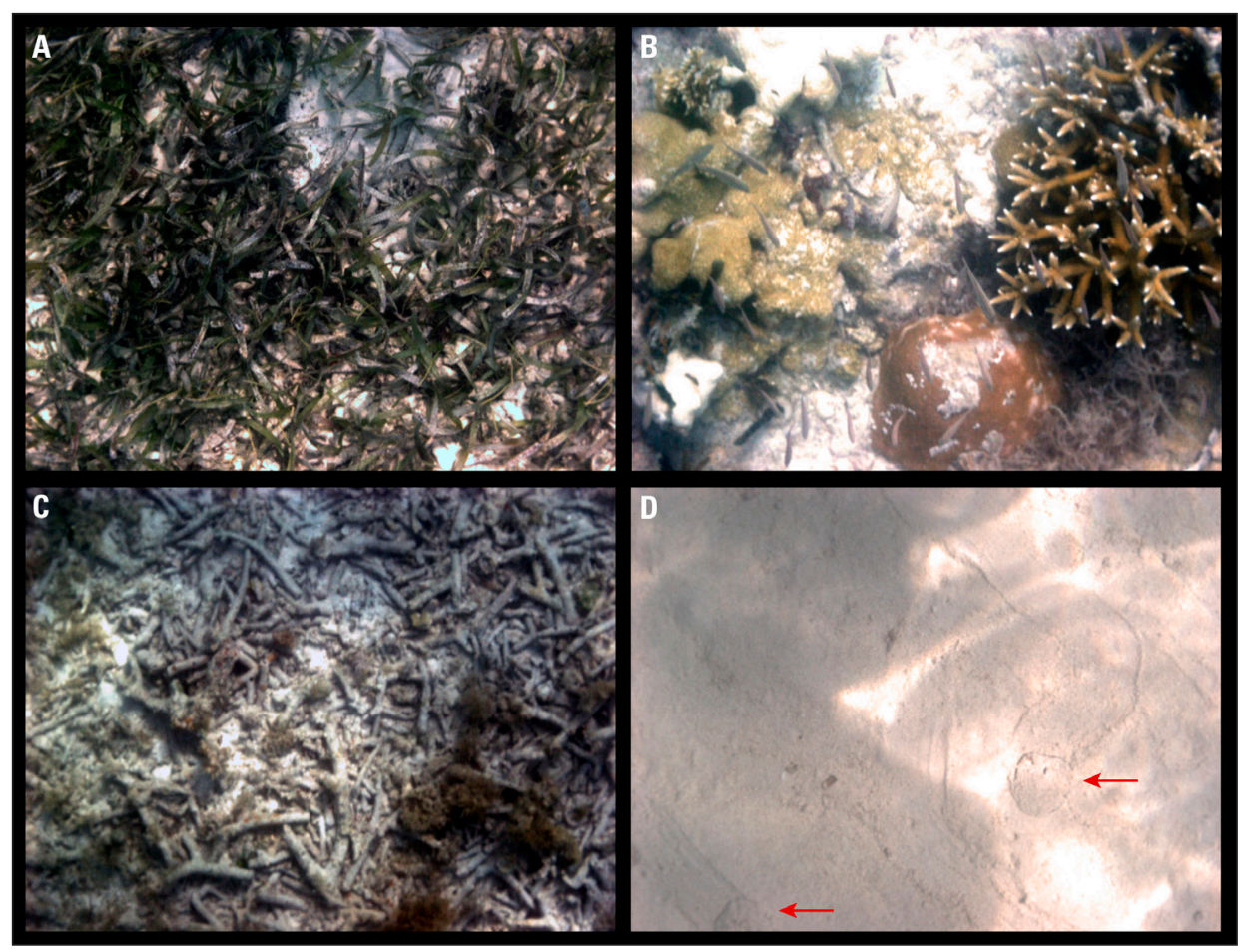

Figure 2. Example ATRIS imagery collected in Dry Tortugas National Park, Florida. (A) Seagrass Thalassia testudinum. (B) Senile reef with identifiable colonies of fire coral (Millepora alcicornis, top left corner), the encrusting zoanthid Palythoa caribaeorum (left side, middle), and staghorn coral (Acropora cervicornis, right side). (C) Rubble consisting primarily of staghorn coral sticks. (D) Sand with tracks of benthic organisms (arrows). Photo credits: David G. Zawada, USGS. 


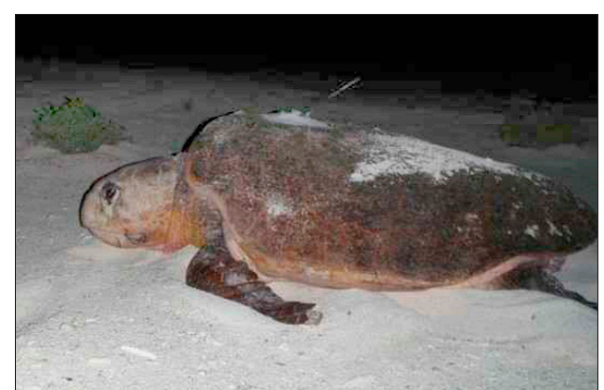

Figure 3. Loggerhead turtle (Caretta caretta) equipped with a satellite tag (top of shell). Photo credit: Kristen M. Hart, USGS.

a $1.0-\mathrm{m} \times 0.78-\mathrm{m}$ area with a 1 millimeter per pixel resolution. Such detailed pictures often allow organisms to be identified to the species level and reveal fine-scale features in the sediment, such as animal tracks (fig. 2). To facilitate image browsing and classification, the ATRIS Data Analysis and Processing Tool (ADAPT) was developed in-house. Written in Python, a platform-independent programming language, ADAPT provides an intuitive graphical user interface and can run under both Mac OS $\mathrm{X}$ and Windows operating systems.

\section{Enhancing Sea Turtle Research with ATRIS Imagery}

An additional benefit of the ATRIS imagery is supporting novel research on threatened loggerhead sea turtles (Caretta caretta). Little is known about the habitat requirements of female loggerhead sea turtles during the time between nesting events, referred to as the inter-nesting period. To monitor the movements and determine habitat-use patterns of loggerheads during the inter-nesting period, we utilized satellite-tracking technology (fig. 3). After nesting, females were intercepted and tagged on the beach at East Key in Dry Tortugas National Park, FL. Using data from two successive nesting seasons in 2008 and 2009, we delineated core-use areas for seven tagged loggerheads during their inter-nesting period (fig. 4). In addition to locating the specific habitats used during this critical time period, we also mapped these areas using shallow ATRIS. From the classified images, we gained an understanding of benthic habitat diversity within the zones preferred by female loggerheads (fig. 5). We are using a similar approach with endangered hawksbill (Eretmochelys imbricata) and green (Chelonia mydas) turtles.

This study is the first to track Dry Tortugas marine turtles via satellite and the first to gather detailed benthic habitat data for loggerhead core-use areas in as close to real-time as possible. Such complementary datasets will improve evaluations of the effectiveness of the park in providing critical habitats for threatened marine turtles, will aid assessments of the condition of those habitats, and will support the development of more effective decisionsupport tools for adaptively managing coral reef ecosystems and U.S. threatened and endangered marine species.

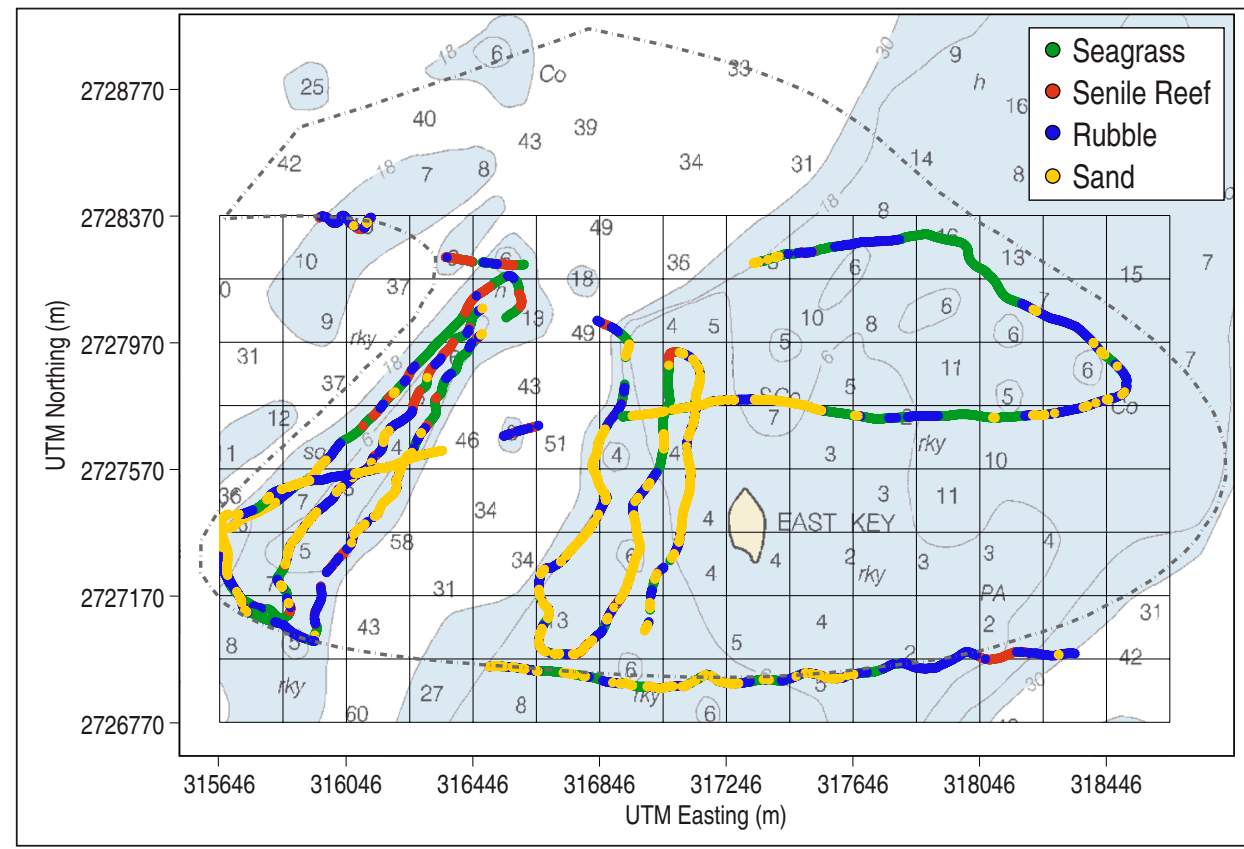

Figure 5. Shallow-ATRIS transect lines are colored according to corresponding benthic habitat as interpreted by Barbara H. Lidz, Geologist, USGS. Scope of the survey was based on the $200850 \%$ core-use area (dashed-dotted gray line; green-shaded area in fig. 4). The grid indicates 200-m x 200-m cells, and depths are given in feet. The underlying map was excerpted from the free digital version of NOAA Raster Navigational Chart \#11438, edition 13.

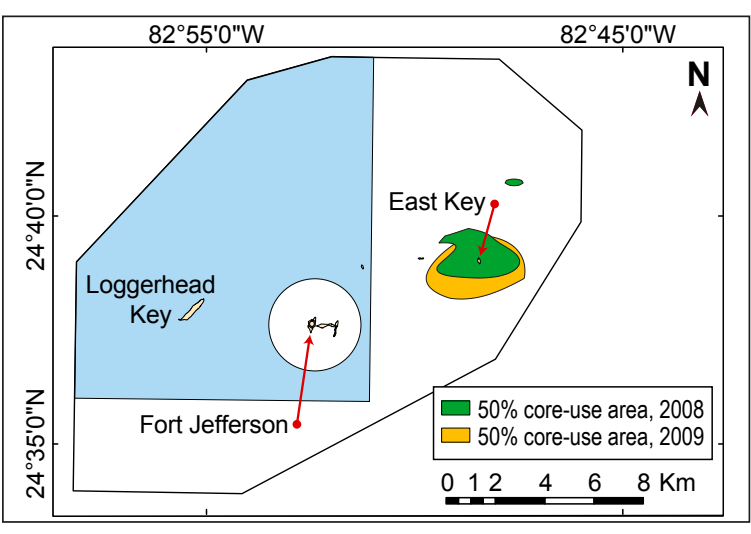

Figure 4. Satellite tag data from 2008-09 were analyzed to determine loggerhead core-use areas where they spent at least $50 \%$ of their time while in Dry Tortugas National Park. Figure courtesy of Ikuko Fujisaki, University of Florida.

\begin{tabular}{|ll|}
\hline Contact Information: & http://coastal.er.usgs.gov/crest/ \\
& \\
ATRIS & Loggerhead Sea Turtles \\
David G. Zawada, Ph.D. & Kristen M. Hart, Ph.D. \\
Research Oceanographer & Research Ecologist \\
U.S. Geological Survey & U.S. Geological Survey \\
St. Petersburg Science Center & Southeast Ecological Science Center \\
600 4th Street South & 3205 College Avenue \\
St. Petersburg, FL 33701 & Davie, FL 33314 \\
Ph: (727) 803-8747 x3132 & Ph: (954) 577-6335 \\
FAX: (727) 803-2031 & Fax: (954) 475-4125 \\
Email: dzawada@usgs.gov & Email: kristen_hart@usgs.gov \\
& \\
\hline
\end{tabular}

References to non-USGS products and services are provided for information only and do not constitute endorsement or warranty, expressed or implied, by the U.S. Government, as to their suitability, content, usefulness, functioning, completeness, or accuracy. 